Kohl: a Journal for Body and Gender Research

Vol. 2, No. 2 (Winter 2016)

\title{
Nothing to Declare
}

\author{
Dictaphone Group
}

Dictaphone Group is a research and performance collective that creates live art events based on multidisciplinary study of space. It is a collaborative project initiated by live artist Tania El Khoury and architect/urbanist Abir Saksouk. Together along with various collaborators such as performance artist Petra Serhal, they have been creating site specific performances informed by research in a variety of places like a cable car, a fisherman's boat, and a discontinued bus. The aim of these projects is to question our relationship to the city, and redefine its public spaces.

dictaphonegroup.com 
Nothing to Declare is a research-based video performance that explores borders within Lebanon, those between Lebanon and its neighbors, and across the Arab world. We took a journey along the abandoned train tracks of Lebanon. Our starting point was a derelict station in Beirut, and continued as each one of us set off on a different trip following one of the three train tracks. Our travels revealed past and present uses of these tracks and the stations that dotted them. Some were abandoned. Others were turned into makeshift housing. Some had the markings of being converted into military bases and torture chambers.

Dictaphone Group showed their video installation of Nothing to Declare at Kohl's launch for this issue. Below is the script of the closing scene of the video.

"People began to call us border-crossers. In reality, we felt trapped between an occupied Palestine, the brutality in Syria and a privatised seashore. Border-crossing became our theatrical act, but sometimes our suicidal act. We learnt that we could not just appear on borders and hope for the best. The mere appearance on some borders may result in detention, disappearance, or death. Each border demands from us a specific performance. Passing through open stretches of no-man's land gave us enough time to rehearse our lines and revisit our appearance. We will have to perform our identity, accents, papers, passports, purposes, class, gender, costumes, voices, and attitudes. We reached the end of our Lebanese journeys following the train tracks."

The trailer in English can be viewed at: https://vimeo.com/64225987 